\title{
DONACIÓn de ÓRgANOS EN PARAgUAY: UNA LEY PARA COMBATIR LOS ÚLTIMOS LUGARES DE AMÉRICA LATINA.
}

'Doctor en Medicina y Cirugía. Universidad Nacional de

Asunción, Paraguay.

Correspondencia a:

Nicolás Ayala- Servín

Correo: nicoayala131292@

gmail.com

Telefono: +595-981-812-911

palabras clave: Obtención de Tejidos y Órganos, Aplicación de la Ley, Trasplante.médica.

Key words: Tissue and Organ Procurement, Law Enforcement, Transplantation

Procedencia y arbitraje: comisionado, no sometido a arbitraje.

Recibido para publicación 18 de febrero de 2020 Aceptado para publicación: 30 de mayol del 2020

Citar como:

Ayala- Servín N. Donación de órganos en Paraguay: Una ley para combatir los últimos lugares de América Latina. Rev Cient Cienc Med 2020; 23(1): 104-104

\section{ORgAN DONATION IN PARAgUAY: A LAW TO COMBAT THE LAST PLACES IN}

\author{
LATIN AMERICA.
}

Nicolás Ayala- Servín

Sr. Editor:

Los estilos de vida y los profesionales del área de la salud, han aumentado la demanda mundial de trasplantes de órganos según la Organización Mundial de la Salud (OMS)'.

Estudios de Europa indican que los principales factores asociados para la donación son la edad, nivel de estudios, la experiencia previa y las actividades prosociales ${ }^{2}$.

Un estudio en España señala que los principales factores independientes asociados hacia la donación de órganos con impacto positivo son la información transmitida por profesionales sanitarios, la discusión familiar sobre el tema, el conocimiento del concepto de muerte encefálica, el conocimiento de la actitud de la parejahacia la donación, y de la actitud hacia la donación de sangre?.

En Paraguay, 224 pacientes se encontraron en el 2018 en lista de espera y precisan procedimientos para seguir viviend ${ }^{4}$. Se presenta una nueva ley donde se estableció la donación directa a partir de los 18 años, a excepción de aquellas personas que dejen constancia de su inconformidad. La ley se basa en el respeto a la voluntad del donante.

La OMS fomenta el desarrollo ético de programas de donación y trasplante; garantizando una regulación y supervisión adecuadas, así como un seguimiento de las prácticas y los resultados de la donación y el trasplante'. No se debe olvidar la educación necesaria para eliminar los tabúes relacionados y así colaborar en el proceso de cambio generacional.

Hoy en día, en cualquier parte del mundo, el tema de donación y trasplante es insuficiente $y$ genera múltiples impactos en la vida de la persona, su familia y la sociedad. Lo que podría ir cambiando con una actitud empática, apoyada bajo un gobierno trasparente $y$ un sistema educativo fortalecido en la salud pública de cada país.
1. OMS / La difusión mundial de los trasplantes de órganos: tendencias, fuerzas impulsoras y repercusiones políticas [Internet]. [Citado: 15 de Enero de 2019]. Disponible en: https://www.who.int/bulletin/ volumes/92/11/14-137653-ab/es/

2. Conesa Bernal C, Ríos Zambudio A, Ramírez Romero $P$, Rodríguez Martínez MM, Canteras Jordana M, Parrilla Paricio P. Importancia de los profesionales de atención primaria en la educación sanitaria de la donación de órganos. Atención Primaria [Internet]. [Citado: 15 de Enero de 2019]; 34(10):52835. Disponible en: http://WwW. sciencedirect.com/science/article/pii/ S0212656704708586

3. Conesa Bernal C, Ríos Zambudio A, Ramírez Romero P, Rodríguez Martínez MM, Canteras Jordana M, Parrilla Paricio P. Estudio multivariante de los factores psicosociales que influyen en la actitud poblacional hacia la donación de órganos. [Internet]. 2005. [Citado 15 de Enero de 2019]; 25(6):684-97. Disponible en: http://www.revistanefrologia.com/espdf-X0211699505019359

4. Si llega tu muerte, no dudes en donar tus órganos para que en el mundo te recuerden siempre Ministerio de Salud Pública y Bienestar Social [Internet]. [Citado: 15 de Enero de 2019]. Disponible en: https://WWW. mspbs.gov.py/portal/15343/si-llegatu-muerte-no-dudes-en-donar-tusorganos-para-que-en-el-mundo-terecuerden-siempre.htm/

5. Ejecutivo reglamenta "Ley Anita", de inscripción automática como donantes. Agencia de Información Paraguaya- Ministerio de Tecnologías de la Información y la Comunicación [Internet]. [Citado: 30 de Julio de 2019]. Disponible en: https://www. ip.gov.py/ip/ejecutivo-reglamentaley-anita-de-inscripcion-automaticacomo-donantes/ 